\title{
Subcellular Spatial Transcriptomes: Emerging Frontier for Understanding Gene Regulation
}

\author{
FURqAN M. FAZAL ${ }^{1}$ AND Howard Y. Chang ${ }^{1,2}$ \\ ${ }^{1}$ Center for Personal Dynamic Regulomes, Stanford University, Stanford, California 94305, USA \\ ${ }^{2}$ Howard Hughes Medical Institute, Stanford University School of Medicine, \\ Stanford, California 94305, USA \\ Correspondence: howchang@stanford.edu
}

\begin{abstract}
RNAs are trafficked and localized with exquisite precision inside the cell. Studies of candidate messenger RNAs have shown the vital importance of RNA subcellular location in development and cellular function. New sequencing- and imaging-based methods are providing complementary insights into subcellular localization of RNAs transcriptome-wide. APEX-seq and ribosome profiling as well as proximity-labeling approaches have revealed thousands of transcript isoforms are localized to distinct cytotopic locations, including locations that defy biochemical fractionation and hence were missed by prior studies. Sequences in the $3^{\prime}$ and $5^{\prime}$ untranslated regions (UTRs) serve as "zip codes" to direct transcripts to particular locales, and it is clear that intronic and retrotransposable sequences within transcripts have been co-opted by cells to control localization. Molecular motors, nuclear-to-cytosol RNA export, liquid-liquid phase separation, RNA modifications, and RNA structure dynamically shape the subcellular transcriptome. Location-based RNA regulation continues to pose new mysteries for the field, yet promises to reveal insights into fundamental cell biology and disease mechanisms.
\end{abstract}

A eukaryotic cell is highly organized, with biomolecules localizing to specific regions of the cell that are integral to their function. For more than three decades, evidence has been accumulating to suggest that the RNAs for thousands of genes show pronounced subcellular localization, and that this localization is an essential mechanism for post-transcriptional regulation. RNA localization influences RNA folding, editing, splicing, degradation, translation, binding partner, catalytic activity, and even the fate of the protein that is encoded. Some of the earliest experiments examining the localization of messenger RNAs (mRNAs) were performed in Xenopus and Drosophila eggs, and were followed by similar demonstrations in yeast, mammalian neurons, and in developing Drosophila embryos. Such studies have revealed that sequences within (i.e., cis elements) RNAs, also termed "zip codes," direct the localization of mRNAs, typically by recruiting proteins (i.e., trans factors).

In this review, we summarize the history of mRNA localization studies and focus on exciting new developments in the last decade to track the localization of thousands of transcripts within cells using either sequencing- or imaging-based approaches. We identify how new techniques are starting to systematically dissect the cis and trans regulators of RNA localization. Although it now appears that RNA subcellular localization is the norm rather than the exception for both coding and noncoding RNAs (Wilk et al. 2016) and is broadly conserved evolutionarily (Benoit Bouvrette et al. 2018), our understanding of the extent, importance, and regulation of subcellular spatial transcriptomics continues to be limited. Further- more, the relevant techniques toolkit for such RNA studies lags behind those developed for subcellular spatial proteomics, for which we have detailed information for more than 10,000 human protein-coding genes with subcellular resolution (Uhlen et al. 2010; Thul et al. 2017) across many tissues (Uhlen et al. 2015). In contrast, even today we do not have a good map or atlas of RNA subcellular localization, although promising new technological developments (Chen et al. 2015; Shah et al. 2016; Fazal et al. 2019) are making such milestones within reach.

\section{BRIEF HISTORY OF RNA LOCALIZATION STUDIES}

Early studies in RNA localization focused on easy-toimage cells such as the relatively large Xenopus (Rebagliati et al. 1985; Weeks and Melton 1987) and Drosophila eggs. Such initial studies established mRNA localization as a way to regulate protein expression and have shown that sequences within the transcript, particularly in the 3' untranslated region (UTR), can direct localization of transcripts; these findings have since been extended to mammalian systems. For example, the Vgl mRNA in Xenopus was found to localize to one (the vegetal) pole, whereas the bicoid mRNA in Drosophila egg cell was shown to localize to the anterior pole and to require the protein Staufen for localization (Fig. 1; St Johnston et al. 1991).

In mammals, one of the most well-studied transcripts is $\beta$-actin mRNA, which localizes to the leading edge of chicken embryo fibroblasts and to the growth cones of

(C) 2019 Fazal and Chang. This article is distributed under the terms of the Creative Commons Attribution License, which permits unrestricted reuse and redistribution provided that the original author and source are credited. 


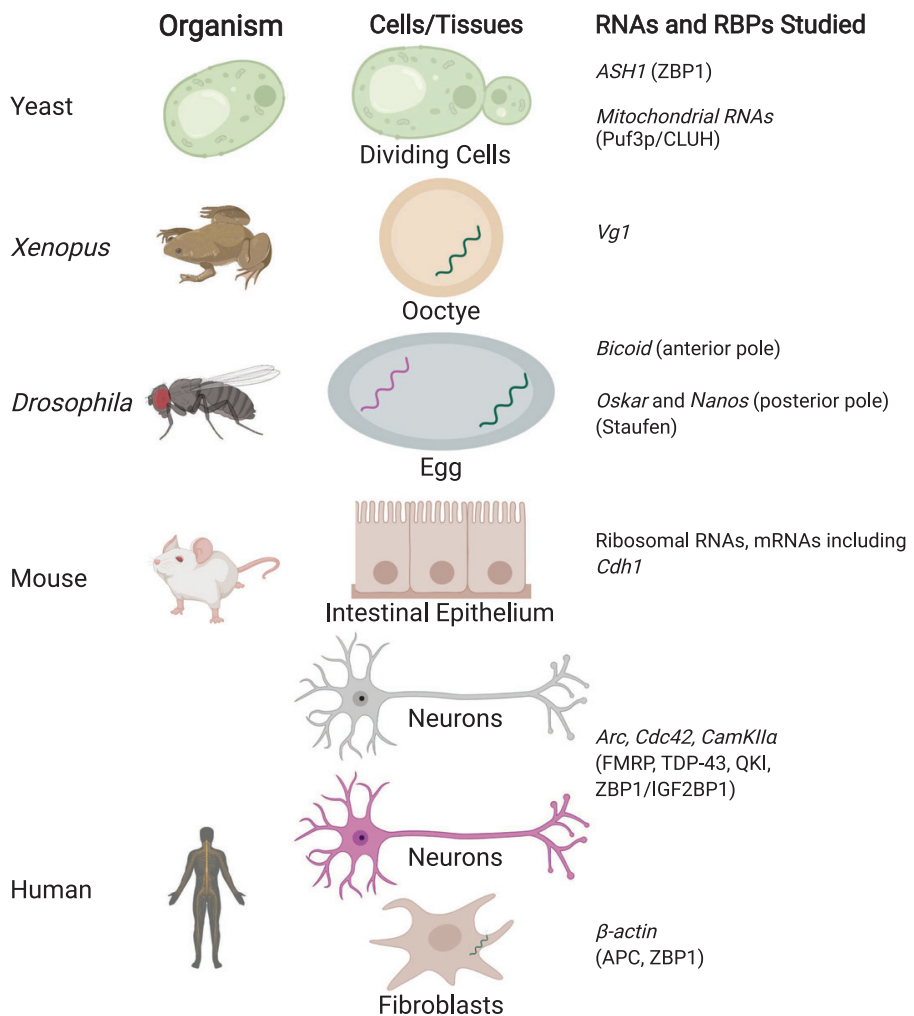

Figure 1. Model systems to study RNA localization. RNA-binding proteins involved are shown in parentheses.

developing neurons. $\beta$-actin has been shown to contain a 54-nucleotide (nt) zip code region in the $3^{\prime}$ UTR that is essential for localization (Kislauskis et al. 1994) in a translation-independent manner. This localization is, in turn, regulated by the protein factors IGF2BP1 (ZBP1) and ZBP2. ZBP1 controls local translation of $\beta$-actin by sequestering the transcript until it reaches the periphery of the cell, where the phosphorylation of ZBP1 releases the mRNA and permits its translation (Huttelmaier et al. 2005). Other RNAs have similarly been shown to localize to cellular protrusions and to require adenomatous polyposis coil (APC) protein (Mili et al. 2008; Baumann et al. 2020). Likewise, the protein fragile $X$ mental retardation protein (FMRP) functions as a translational regulator of localized RNAs in many systems, including neurons and fibroblasts (Mili et al. 2008). FMRP functions by binding to and repressing the translation of mRNAs and is mediated by recognition of RNA secondary structure. Upon reaching their destination, FMRP release of the RNAs triggers local translation, as in the case of axons. Findings from many studies have converged on the hypothesis that the mRNAs are transported along with retinol-binding proteins (RBPs) in the cytosol as translationally repressed RNA granules (Anderson and Kedersha 2006). Supporting studies have shown that the cytoskeleton and its associated molecular motors play an integral role in this mRNA transport (Wang et al. 2016).

The lessons learned to dissect $\beta$-actin mRNA transport have since been extended to other mammalian systems, particularly neurons that are ideal systems to study locali- zation defects because of the vast distances metabolites need to be transported. Neurons need to coordinate functions between the cell nucleus and the axons and dendrites, which can be $>1 \mathrm{~m}$ apart. Neurons also need to dynamically regulate their proteomes in response to changing environments, and it is now clear that local translation of mRNAs in dendrites is widespread and essential. It is now thought that RNA localization is the primary determinant of the proteome of neurites, rather than transport of corresponding proteins (Zappulo et al. 2017). Furthermore, many essential RBPs whose processing is dysregulated in neuronal disorders have been shown to bind hundreds of RNAs and to be involved in their localization. Two such RBPs are FMRP, whose loss of function results in fragile X syndrome and autism, and TDP-43, whose dysregulation is associated with amyotrophic lateral sclerosis (ALS) (Neumann et al. 2006; Sreedharan et al. 2008). TDP-43, which regulates RNA metabolism through many mechanisms, will form cytoplasmic messenger ribonucleoprotein (mRNP) granules that undergo microtubuledependent transport in neurons (Fig. 2; Alami et al. 2014).

\section{MECHANISMS OF RNA LOCALIZATION}

\section{Role of cis Elements, including Retrotransposable Elements and Features in the 3' UTR}

Studies focusing on specific RNAs such as $\beta$-actin have revealed that mRNAs can localize to subcellular locales independent of translation and are guided by internal zip 


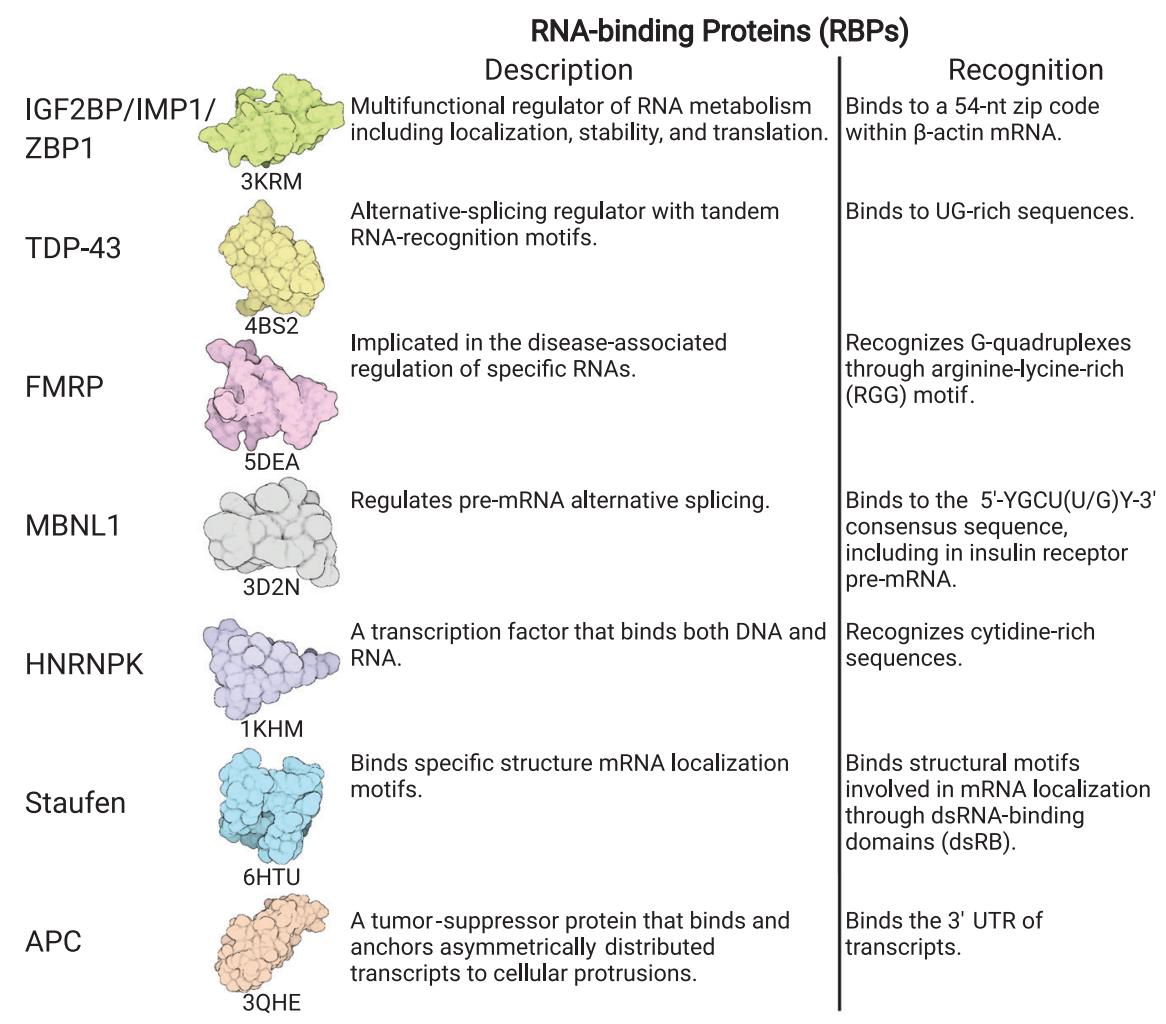

Figure 2. Some representative RNA binding proteins implicated in mRNA localization. Structures are generated from Protein Data Bank (PDB) entries.

code sequences, particularly in 3' UTRs. Surprisingly, even smaller RNAs such as microRNAs (miRNAs) can contain sequence elements within that direct them to subcellular locales (Hwang et al. 2007), as do many long noncoding RNAs (lncRNAs) (Batista and Chang 2013). However, for the vast majority of transcripts, the zip codes responsible for localization to specific organelles and biological condensates remain unknown, although newly developed transcriptome-wide approaches are laying the foundation for identifying more cis- localization elements. For example, in neurons, hundreds of genes, including $C d c 42$, have transcript isoforms that localize differently between neurites and the soma based on sequence differences in 3' UTRs (Ciolli Mattioli et al. 2019). Similarly, the endoplasmic reticulum (ER) is known to recruit transcripts directly in a translation-independent matter (Pyhtila et al. 2008), and a recent transcriptome-wide study has identified a sequence termed SECRETE that can recruit mRNAs encoding secretory/membrane proteins to the ER. The SECRETE sequence, comprising a $\geq 10$-nt triplet repeat, occurs in both prokaryotes and eukaryotes (CohenZontag et al. 2019).

A robust approach to identify zip codes within transcripts, which has been particularly fruitful for lncRNAs, is to identify a transcript(s) that localizes to a specific locale and then to systematically test whether sequences within are necessary and sufficient to direct localization (Fig. 3). Such an approach has identified an $~ 600$-nt region in human cells that is required for localization of the
lncRNA MALAT1 to nuclear speckles (Miyagawa et al. 2012). Similarly, sequences within the lncRNA Xist called A-repeats, located near the $5^{\prime}$ end, are responsible for localization to the nuclear periphery (Wutz et al. 2002), likely secondary to the ability of this RNA element to induce facultative heterochromatinization (Chaumeil et al. 2006). Another lncRNA Firre has a 156-nt repeating RNA domain (RRD), recognized by the protein hnRNPU, that aids in localizing it to chromatin (Hacisuleyman et al. 2014); hnRNPU binding is also required for the proper localization of Xist (Hasegawa et al. 2010). Recently several studies, including computation and experimental approaches, have revealed that sequences derived from transposable elements, which are present in many mRNAs and lncRNAs, contribute to the nuclear retention of many lncRNAs (Carlevaro-Fita et al. 2019). Although such studies show the widespread occurrence of zip code sequences, systematic high-throughput experiments are needed to identify the cis elements necessary for the observed extensive RNA subcellular localization transcripts.

\section{Protein Factors That Interact with mRNAs and IncRNAs}

RNA localization is thought to be orchestrated by RNAbinding proteins that can recognize sequence motifs or RNA structural features, including single-stranded regions or stem loops. Although we know of a few RBPs mediating localization, including Staufen and Puf3, how the cell co- 


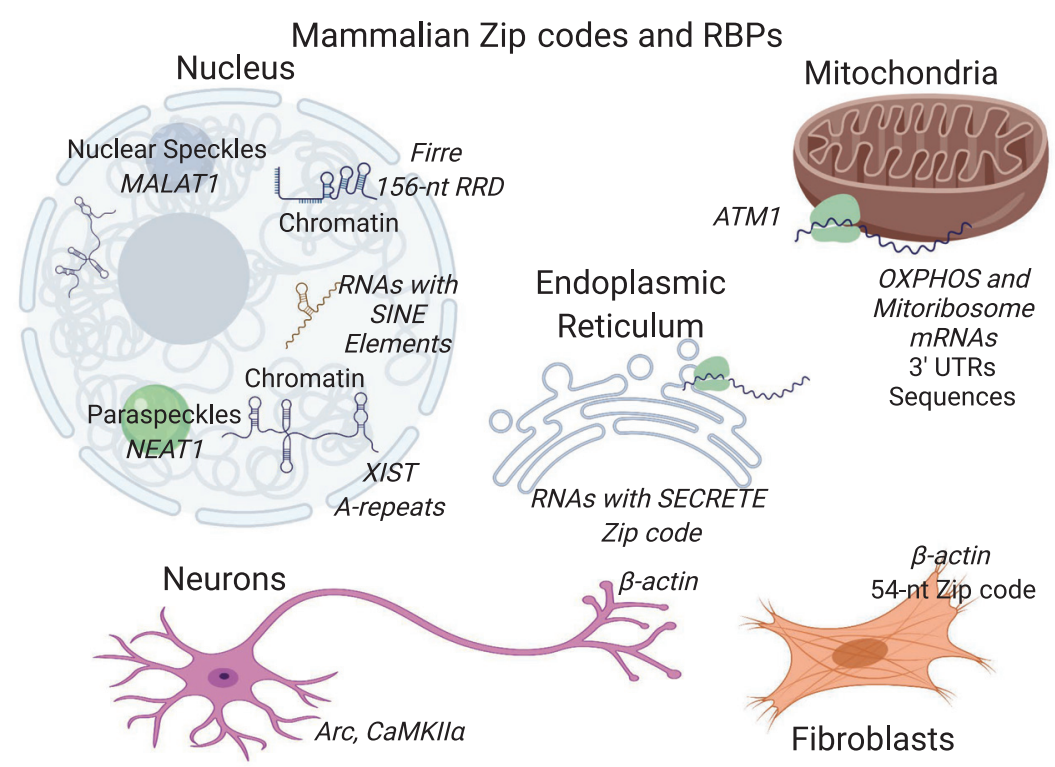

Figure 3. Examples of locales with localized RNAs and associated zip codes.

ordinates the localization of thousands of transcripts remains poorly understood. In the case of Staufen, binding to double-stranded sequences within maternal RNAs ( $\mathrm{St}$ Johnston et al. 1992) results in their subcellular localization, whereas for the Puf3 protein binding to a sequence motif (Zhu et al. 2009) within some nuclear-encoded RNAs results in their recruitment to the mitochondria in yeast (Saint-Georges et al. 2008; Gadir et al. 2011). Future work on mapping RNA-protein interactions (Ramanathan et al. 2019) will likely be crucial in discovering RBPs essential for localization.

\section{Active Transport and the Role of Molecular Motors}

Many studies suggest mRNA localization in the cytosol is facilitated by the underlying cytoskeleton network, although the relative contributions of individual players remain unclear. However, we do know that molecular motors operating on microtubules as well as actin filaments participate in RNA transport (Fig. 4; Maday et al. 2014), including myosin motors that walk on actin filaments and kinesins and cytoplasmic dynein that move on microtubules. For example, early studies established that the localization of oskar mRNA in Drosophila oocytes to the posterior pole requires the cytoskeleton (Erdelyi et al. 1995), with subsequent studies implicating kinesin-1 (Zimyanin et al. 2008). Similar studies of other RNAs in yeast have implicated myosin V (Bertrand et al. 1998).

Furthermore, this RNA localization process can be dynamically regulated through active transport, as shown in intestinal epithelial cells where mRNAs strongly localize (Moor et al. 2017). The RNA, packaged in RNPs, can be transported bidirectionally along microtubules by plusend-directed kinesins (Kanai et al. 2004) and minus-enddirected dynein motors (Hirokawa et al. 2010). Kinesins typically transport RNAs toward the cell periphery, whereas dynein transports RNAs toward the cell center (retro- grade transport). However, how the different motors cooperate is unclear, and in fact, different motor types are known to engage cargo and participate in tug-of-war coordination (Hancock 2014). A recent transcriptomewide study has confirmed that hundreds of transcripts rely on microtubule-based transport to get their cytosolic destinations (Fazal et al. 2019), and continued progress is being made in understanding the transport of RNAs, as shown in reconstituted in vitro systems (Baumann et al. 2020) and inside living cells (Krauss et al. 2009).

\section{Splicing, Intron Retention, and Nuclear Export}

The nucleus of a eukaryotic cell is enveloped by a double lipid bilayer that serves as the gateway for mRNAs exiting to the cytosol. The export of RNAs through the nuclear pore complexes (NPCs) spanning the envelope has been extensively studied (Muller-McNicoll and Neugebauer 2013; Katahira 2015), with translocation through the pore thought to be diffusive, and with only a fraction (one-third or less) of mammalian mRNAs that interact with the NPC eventually exiting (Ma et al. 2013). Importantly, this export process can vary depending on the type of RNA species (mRNAs, ribosomal RNAs [rRNAs], micrmiRNAs, transfer RNAs [tRNAs], etc.) in question (Muller-McNicoll and Neugebauer 2013; Katahira 2015). Furthermore, mRNAs can move bidirectionally through the pore, and not all pores are created equally (Grunwald and Singer 2010; Siebrasse et al. 2012). The NPCs are hypothesized to show considerable heterogeneity (Colon-Ramos et al. 2003), with specialized NPCs mediating the transport of mRNAs from distinct genomic loci with nuclei to specific regions of the cytosol and, therefore, optimizing nuclear export and facilitating subsequent translation (Brown and Silver 2007).

Within the nucleus, splicing has a profound influence on nuclear export (Kim-Ha et al. 1993; Hachet and Eph- 

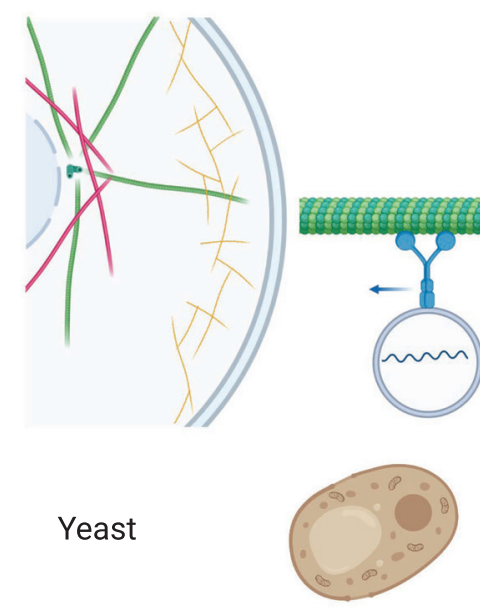

Invertebrates

Invertebrates

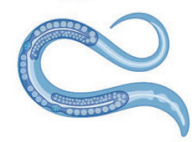

Mammals

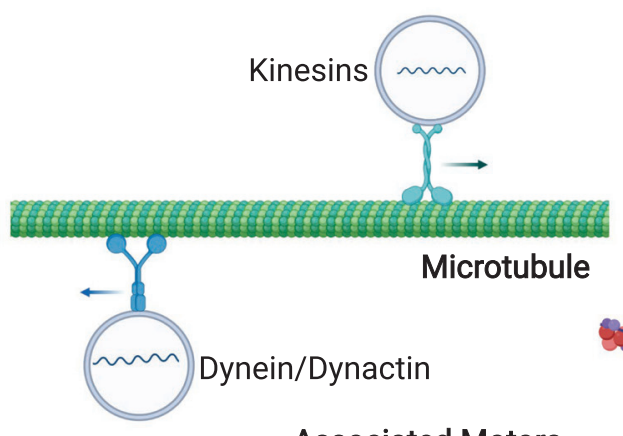

Associated Motors

Myosin-V (Myo4/She2)

F-actin Nanos

Dynein-1, Myosin-V

Kinesin 1, Kinesin-2

KIF11, Myosin-Va, Myosin -IB

Kinesin-1 (KIF5)

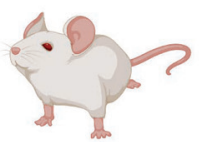

F-Actin

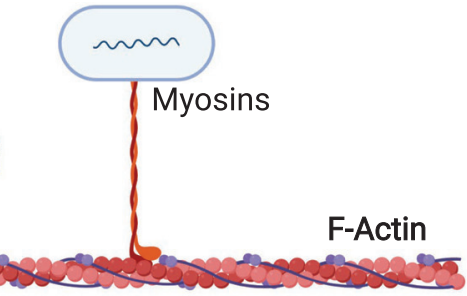

mRNAs

Kinesin-1 (KIF5)

Vg1

$\beta$-actin

MAP1B, CaMKIIa

Figure 4. Molecular motors implicated in RNA transport.

russi 2004), with pre-mRNAs recruiting splicing factors along with the conserved mRNA export machinery (TREX, transcription/export complex). TREX is recruited to the $5^{\prime}$ end of transcripts and accounts for the export of mRNAs through the pore (Cheng et al. 2006). Likewise, the deposition of exon-junction complex (EJC) during splicing is essential for the localization of developmentally important transcripts (Braunschweig et al. 2013), including oskar mRNA in Drosophila (Ghosh et al. 2012). Alternative splicing provides yet another opportunity for the cell to influence RNA localization, as has been shown recently where isoform-specific localization to neurites is guided by alternative last exons (ALEs) (Taliaferro et al. 2016). Furthermore, partial splicing of transcripts results in their nuclear retention, which partially explains why many lncRNAs that are substantially lessefficiently spliced relative to mRNAs are nuclear (Zuckerman and Ulitsky 2019). By retaining some introns ("detained introns") in polyadenylated transcripts that are only excised before export, cells use nuclear retention in mRNAs and a constant nuclear-export rate to reduce cytoplasmic gene expression noise due to bursty transcription-related noise (Bahar Halpern et al. 2015). Such detained introns are widespread, enriched in UTRs and noncoding RNAs, and thought to functionally tune transcriptomes (Braunschweig et al. 2014).

\section{MODERN APPROACHES TO STUDY RNA LOCALIZATION}

\section{Tracking Single RNAs}

Currently, there are two general approaches to map RNA subcellular localization: imaging- and sequencing- based. Imaging-based approaches over the last two decades have yielded insights into the dynamics of single RNAs in cells, revealing their complicated history. One of the early studies focused on the dynamics of $A S H 1$ mRNA in yeast, and its $3^{\prime}$ UTR localization using the MS2 RNAhairpin system (Fig. 5; Bertrand et al. 1998). Since then, the MS2 system has been optimized and applied extensively to study mRNA localization and transcription in living cells (Darzacq et al. 2007), and complementary approaches have been developed (Wu et al. 2016, 2019; Braselmann et al. 2018; Chen et al. 2019a; Wan et al. 2019) to study localization and local translation. Similar studies have revealed the intricate dynamics of nuclear pore mRNA export (Grunwald and Singer 2010; Siebrasse et al. 2012; Chen et al. 2017), and the trafficking of mRNAs to membrane-less organelles (MLOs) such as stress granules (Nelles et al. 2016). In addition to live-cell imaging, in situ hybridization approaches (Lawrence et al. 1989), which have evolved to use fluorescent in situ hybridization (FISH) labeling (Femino et al. 1998), provide complementary information with routine single-molecule sensitivity (Raj et al. 2008). The FISH-based approach has recently been extended to study RNA localization for hundreds of thousands of RNAs simultaneously, as discussed below.

\section{Transcriptome-Wide Imaging Technologies}

An exciting development in the field is the new approaches that finally enable imaging of hundreds and even thousands of RNAs within fixed cells. An early study was based on in situ RNA sequencing using complementary DNA amplicons, which permitted thousands of 


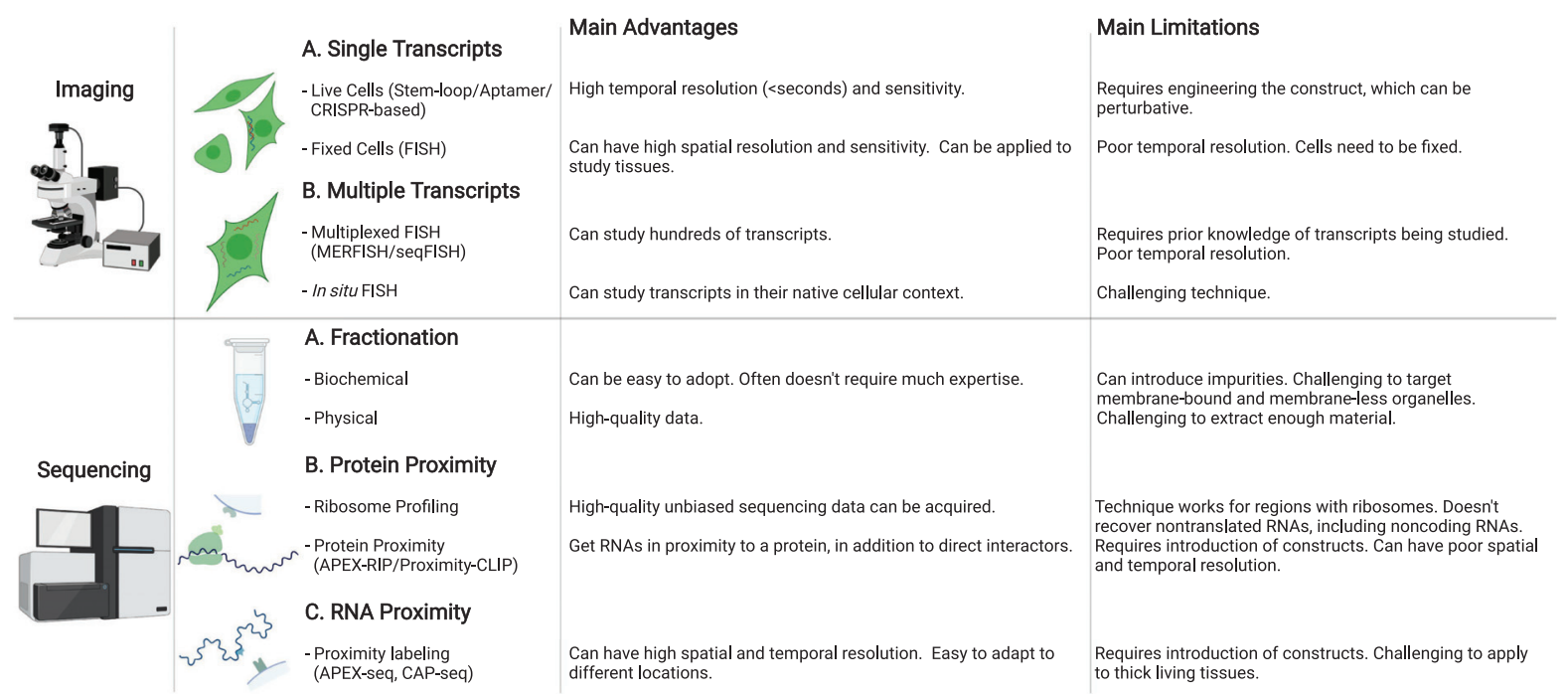

Figure 5. Techniques to study RNA localization.

RNAs to be simultaneously interrogated (Lee et al. 2014). However, although this technology is promising (Ke et al. 2013; Lee et al. 2014) and improvements continue to be made (Fürth et al. 2019), so far this challenging approach has not been widely adopted. Instead, visualizing many RNAs using sequential FISH is at the forefront of highthroughput localization studies, and two groups have mainly advanced this approach. In one iteration, called MERFISH developed by the Zhuang laboratory, the locations of RNAs in fixed cells are interrogated by performing sequential FISH through multiple rounds of hybridization of DNA oligonucleotides ("oligos") to the complementary RNAs of interest. This sequential approach uses an error-correcting scheme to design and select for hybridization oligos, such that some errors in the binding of DNA oligos to the complementary RNA molecules can be tolerated and correctly decoded. Although the high density of RNAs in a cell puts a limit on how many transcripts can be resolved and their relative abundances (Chen et al. 2015), in practice, hundreds to thousands of transcripts in individual cells can be interrogated. Further advances, including the integration of other techniques such as expansion microscopy, have further aided throughput (Xia et al. 2019). Recently the MERFISH approach has also been extended to carry out phenotypic screening in cells (Emanuel et al. 2017), as shown by a study identifying positive and negative regulators of the nuclear-speckle localization of the lncRNA MALAT1 (Wang et al. 2019a).

The second sequential FISH approach, advanced by Cai and coworkers, called SeqFISH (Lubeck et al. 2014; Shah et al. 2016), allows multiplexed imaging of hundreds of genes through signal amplification and error-correction schemes, similar to MERFISH. Excitingly, SeqFISH facilitates mapping the subcellular localization of thousands of RNAs, including nascent transcripts (Shah et al. 2018) and splice isoforms. However, the limitations of both MERFISH and SeqFISH include working with fixed and not live cells. Furthermore, unlike sequencing that can be unbiased, the techniques require prior knowledge of the transcripts being targeted, as oligos can be designed to image those transcripts. In the near term, the unique advantage of imaging-based approaches in simultaneously interrogating many cells makes them especially well suited in exploring RNA heterogeneity across cells and in tissues (Moffitt et al. 2018), thereby distinguishing cell-types based on the RNAs they express (Eng et al. 2019).

\section{Transcriptome-Wide Sequencing Technologies}

The advent of next-generation sequencing technologies has ushered in a new revolution in biology, including in the investigation of RNA localization. Biochemical fractionation protocols coupled with RNA sequencing have, for example, been applied to study nuclear-versus-cytosol RNA dynamics (Djebali et al. 2012; Benoit Bouvrette et al. 2018) and to determine RNAs being actively translated through polyribosome profiling. In recent years, fractionation protocols have also been developed to determine the RNAs in challenging locations such as the membraneless nucleolus and stress granules (Khong et al. 2017). Likewise, physical/mechanical separation of long neuronal cells, typically through microdissection (Cajigas et al. 2012), has been productive in determining their transcriptomes. Other techniques such as laser capture microscopy (LCM) have also enabled careful dissection of both single cells and subcellular locations (Nichterwitz et al. 2016) within and been applied to study rapid changes in RNA localization in mouse intestinal epithelial cells in response to food gradients (Moor et al. 2017).

An innovative approach to study the RNAs in cytosolic locales such as the endoplasmic reticulum membrane (ERM) and outer mitochondrial membrane (OMM) has been through proximity-specific ribosome profiling, in which ribosomes in specific locations undergo proximity biotinylation (Roux et al. 2012). These ribosomes with a 
biotin tag can subsequently be isolated through streptavidin-biotin pulldown, and the RNAs they are bound to and translating profiled by sequencing them. Such ribosome profiling experiments have revealed the RNAs bound to ribosomes in the ER in yeast and humans (Jan et al. 2014) and at the outer surface of the mitochondria in yeast (Williams et al. 2014; Costa et al. 2018).

Despite these existing sequencing technologies, many critical locations within the cell, including membranebound and membrane-less organelles, continue to be difficult, if not impossible, to interrogate. Furthermore, unlike live-cell-imaging approaches, these sequencingbased approaches are generally not well suited to study the dynamics of transcript localization. However, a new approach discussed below using proximity labeling of RNAs in living cells provides an opportunity to investigate RNA subcellular spatial dynamics (Fazal et al. 2019; Padron et al. 2019), albeit currently at a bulk rather than single-cell scale.

\section{Subcellular Transcriptomics through Proximity Labeling}

A recent approach to determine the RNAs at subcellular locales, called APEX-seq, yields an unbiased transcriptome that can be applied to study membrane-less and membrane-bound organelles. APEX-seq leverages an engineered enzyme called APEX2 (ascorbate peroxidase, version 2) that can be targeted to specific cellular locales by fusing it to a protein or peptide that is known to localize to the desired location. Upon providing the reagents biotin-phenol and hydrogen peroxide, APEX2 generates biotin-phenoxy radicals that result in the spatial tagging of nearby metabolites within cells with a biotin tag (Rhee et al. 2013). For example, when plasmids containing APEX2, which itself is around the size of green fluorescent protein (GFP), are fused to the nuclear localization sequence (NLS) and introduced into cells, APEX2 localizes to the nucleus and permits tagging of metabolites there. These metabolites include proteins (Rhee et al. 2013), RNAs, DNA, and small molecules; in APEXseq, the labeled RNAs are isolated and enriched for using streptavidin-biotin pulldown, followed by RNA sequencing. Excitingly, APEX RNA labeling can achieve high spatial $(\sim 10-\mathrm{nm})$ and temporal $(\sim 1-\mathrm{min})$ resolution in almost any location of interest, including in MLOs such as the nucleolus (Fazal et al. 2019) and stress granules (Markmiller et al. 2018), as well as the membrane-bound ER (Kaewsapsak et al. 2017) and outer mitochondrial membrane (Fazal et al. 2019). Furthermore, APEX-based approaches have been applied to different model systems, including in mice, worms, and flies, as well as in cultured neurons (Hung et al. 2016). Likewise, fusing APEX to dCas9 (Gao et al. 2018; Myers et al. 2018; Qiu et al. 2019) allows targeting APEX to any genomic locus and obtaining the interacting proteins and RNAs.

In the initial demonstrations of obtaining subcellular RNAs using proximity labeling, APEX was used to label proteins, which were then cross-linked with RNAs nearby.
These biotin-labeled proteins were then enriched by streptavidin-biotin pulldown, and the cross-linked RNAs were released and sequenced. Using this cross-linking approach, called APEX-RIP (Kaewsapsak et al. 2017) and proximityCLIP (Benhalevy et al. 2018), APEX labeling has been used to determine the RNAs in the cytosol, nucleus, and mitochondria. In APEX-RIP, formaldehyde cross-linking is performed, whereas in proximity-CLIP UV cross-linking and metabolic labeling is used to improve specificity.

In contrast, the more straightforward APEX-seq approach entailing direct RNA labeling (Zhou et al. 2019) has generated subcellular transcriptomes of many organelles in human cells (Fazal et al. 2019; Padron et al. 2019). By targeting APEX to multiple subcellular locales in the nucleus and cytosol, APEX-seq has revealed that thousands of RNAs show robust subcellular localization (Fazal et al. 2019). Independently, Ingolia and coworkers have used APEX-seq to examine RNAs in proximity to the 7-methylguanosine $\left(\mathrm{m}^{7} \mathrm{G}\right)$ cap-binding protein eIF4E1, while also obtaining subcellular proteomic information. In addition, changes in RNA localization upon heat shock and stress granule assembly on the timescale of minutes were tracked (Padron et al. 2019).

APEX-seq (Fazal et al. 2019) has revealed that the RNA transcripts for thousands of genes localize to specific locales within cells, including in the nucleolus, nuclear lamina, nuclear pore, OMM, and ERM. Moreover, APEX-seq detected many transcripts with distinct isoforms showing differential subcellular localization. In addition to providing a map of subcellular RNA localization, APEX-seq has confirmed the role of the nuclear pore in mRNA surveillance and shown that the location of mature RNA transcripts within the nucleus is connected with the underlying genome architecture. For example, transcripts found at the nuclear lamina are enriched for genes found in DNA lamina-associated domains (LADs), as well as transcripts containing retrotransposable elements such as the short interspersed nuclear elements (SINEs) and long interspersed nuclear elements (LINEs). APEX-seq also revealed two modes of mRNA localization to the OMM: ribosome-dependent (i.e., requiring translation) and RNA-dependent. Transcripts coding for mitochondrial proteins that localize to the OMM independent of translation were found to have shorter $3^{\prime}$ UTRs and shorter poly(A) tails. RNA localization to the OMM depends on active transport, as shown by time course experiments showing mislocalization of transcripts within minutes of adding nocodazole, a microtubule depolymerizer.

APEX-seq, in conjunction with approaches to identify proteins interacting with specific RNAs (Chu et al. 2015; Ramanathan et al. 2018, 2019; Mukherjee et al. 2019; Han et al. 2020), is likely to emerge as a powerful approach to identify both localized RNAs and their corresponding RBP partners. Likewise, new approaches to spatial tagging of RNAs are continually being invented. One such method is based on spatially restricted nucleobase oxidation, which uses localized fluorophores ( $\mathrm{Li}$ et al. 2017). Another approach uses an enzyme to add uridine residues to RNAs in specific locations in Caenorhabditis elegans, including in the mitochondria and ER (Medina-Muñoz 
et al. 2019). A third approach, called CAP-seq, uses lightactivated, proximity-dependent photo-oxidation of RNA (Wang et al. 2019b).

\section{Machine-Learning Approaches}

Subcellular RNA-seq data, including from the nucleus, cytosol, and the ER, provide rich data sets to identify the sequencing elements involved in RNA localization. Applying machine-learning approaches, including deeplearning algorithms (LeCun et al. 2015), to these data sets is likely to provide new insights into the sequencedeterminants of localization (Fig. 6). For example, bioinformatics approaches have identified transposable elements as being important for the nuclear retention of many lncRNAs (Carlevaro-Fita et al. 2019). Furthermore, a statistical analysis has shown that the transposable element Alu has a strong preference for being in the 3' UTR of transcripts that are overrepresented in the nucleus, Golgi, and mitochondria (Chen et al. 2018). Similarly, a deep- neural-network approach to predict lncRNA localization as nuclear or cytosolic directly from transcript sequences had modest success, approaching an accuracy of $72 \%$ (Gudenas and Wang 2018). In that study, the feature set for learning included sequences as $k$-mers, known RNAbinding protein motif sites, as well as genomic characteristics of the RNAs such as whether they were intergenic, antisense, or sense lncRNAs. Likewise, another group used $k$-mers along with other features to obtain an accuracy of 59\% for localization of lncRNAs (Cao et al. 2018), although another group in a different context claimed $87 \%$ accuracy using 8-mer nucleotide segments along with other features (Su et al. 2018). Another model called RNATracker has used a convolutional neural network to classify RNA localization; so far, success has been modest (Yan et al. 2019). A recent computational approach called RNA-GPS (Wu et al. 2020), which uses an APEX-seq data set (Fazal et al. 2019) comprising the subcellular transcriptome of eight locations, uses $k$-mers as features to obtain an overall accuracy of $70 \%$. RNA-GPS implicates transcript splicing as an important process influencing localization

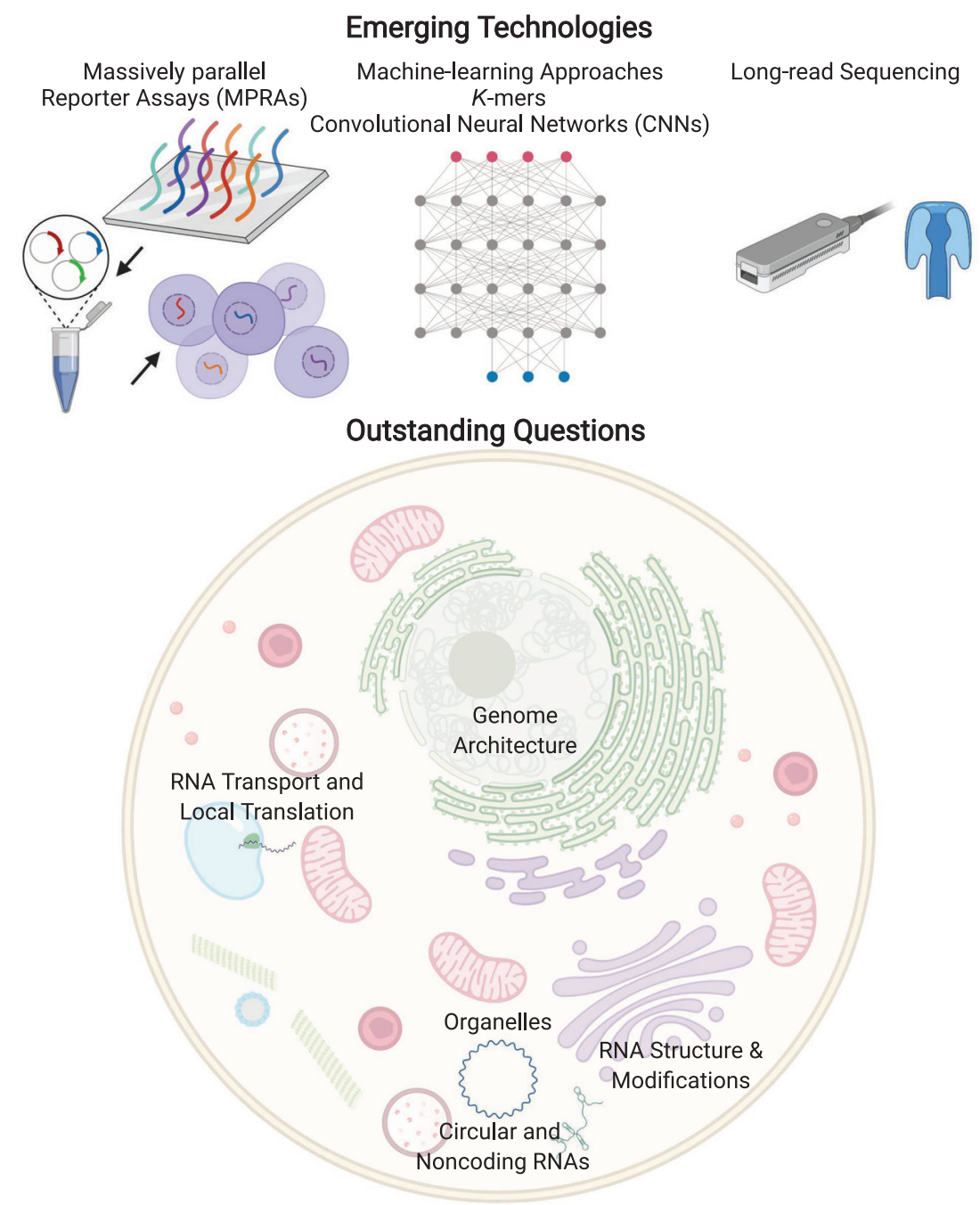

Figure 6. The latest approaches and outstanding questions in investigating RNA localization. 
for organelles within both the nucleus and cytosol. In summary, although such approaches are in their infancy, they should provide candidates sequences that can be directly tested for their localization potential, and the corresponding interacting RBP identified (Wu et al. 2020).

\section{Massively Parallel Reporter Assays}

An experimental strategy to identify and test for zip code sequences within cells is the use of massively parallel reporter assay (MPRAs), in which tens of thousands of sequences, typically 75-200 nt in length, can be interrogated. Using MPRAs, along with machine-learning models, particularly convolutional neural networks (CNNs) (Movva et al. 2019), is likely to facilitate the rapid discovery of zip code sequences. Two groups recently used highthroughput screens to identify cis-acting RNA localization elements that promote nuclear retention. Rinn and coworkers tested and designed more than 10,000 oligos derived from 38 human lncRNAs with known both nuclear and cytosolic localization. Similarly, the Ullitsky group used approximately 5500 oligos gathered from 37 lncRNAs as well as some mRNAs. Both these studies were performed by introducing these oligos into an RNA and assessing its change in nuclear retention by nuclear-cytosolic fractionation following by sequencing. Through the MPRA experiments, the Ulltisky group found a cytosine-rich element, $\operatorname{RCCTCCC}(\mathrm{R}=\mathrm{A} / \mathrm{G})$, derived from an antisense Alu element, which they named SIRLOIN (SINE-derived nuclear localization element), that promotes nuclear retention (Lubelsky and Ulitsky 2018). By screening the binding sites of more than 100 RBPs using publicly available RBP-binding data sets (Van Nostrand et al. 2016), they identified the heterogeneous nuclear ribonucleoprotein K (HNRNPK) as binding to and nuclear-retaining SIRLOIN-containing RNAs. The Rinn group found a similar motif contributing to nuclear retention. The role of SINE elements in nuclear retention of MALAT1 lncRNA through HNRNPK recruitment was recently confirmed by another study (Nguyen et al. 2020).

MPRA-based screens are likely going to be a powerful way to screen for zip code components, including sequence motifs and structural elements. Concomitantly, MPRA experimental and computational strategies continue to improve, and it is now possible to test more than 100 million sequences (de Boer et al. 2019).

\section{Long-Read Sequencing}

Next-generation-sequencing (NGS) approaches, including using the Illumina platform, continue to transform in biology. However, a significant limitation continues to be the relatively short sequencing reads (typically $<300$ basepair [bp]) generated. Fortunately, the latest third-generation approaches such as Oxford Nanopore Technologies (ONT) and Pacific Biosciences (PacBio) provide much longerread sequencing reads ( $>1000 \mathrm{bp}$ ) and can sequence RNA directly without having to reverse transcribe it to make complementary DNA (cDNA) (Garalde et al.
2018). By being able to generate full-length transcript sequences, in addition to yielding RNA modification (Soneson et al. 2019; Workman et al. 2019), these techniques can reveal the landscape of variation in splicing isoforms, poly(A)-tail-length (Legnini et al. 2019), and RNA modifications (Workman et al. 2019). Exciting future studies will undoubtedly implement these approaches to explore transcript-isoform localization differences and dissect the role of RNA modifications in localization. Previous studies indeed identify the abundant N6-methyladenosine $\left(\mathrm{m}^{6} \mathrm{~A}\right)$ modification to be important for facilitating the nuclear export of mRNAs, with modified transcripts "fast-tracked" to the cytosol for translation (Lesbirel and Wilson 2019).

\section{SOME OUTSTANDING QUESTIONS IN THE FIELD}

Although RNA localization studies have a rich history spanning more than three decades, many critical issues in the field remain unanswered. The central question continues to persist: Why do cells localize their RNA contents? In some cell types, such as neuronal cells in which the distances involved for transporting biomolecules are vast, it is easy to rationalize that actively transporting mRNAs to their destination to be locally translated to make proteins would be convenient and efficient. However, it remains unclear why RNA subcellular localization is ubiquitously observed in almost all cell types, including ones in which the process of diffusion should be fast (seconds or less). To address the question of why cells localize their RNA contents, we must first explain the following questions.

\section{Relative Contribution of Translation- versus RNA-Dependent mRNA Localization}

A vital issue in the field is ascertaining to what extent the observed subcellular RNA localization is translationdependent, and whether RNAs can be transported, particularly actively by molecular motors, with the ribosome engaged in the translation of the mRNA. It was generally accepted that the transport of mRNAs occurs through mRNPs that are translationally repressed until they get to their destination (Fig. 6). Furthermore, translating mRNAs interact with RNP granules dynamically, whereas nontranslating mRNAs can form stable associations (Moon et al. 2019). However, recent studies have begun to question this assumption, including imaging experiments that have revealed that active transport of mRNAs can occur after the mRNA has started translation and entered the polysome state (Wang et al. 2016; Moon et al. 2019). Similarly, APEX-seq has revealed that many nuclear RNAs destined for the mitochondria begin the process of translation elsewhere, such as in the cytosol, and then the translating-ribosome complex comprising of the nascent peptide being synthesized, RNA, and ribosome is directed to the mitochondria. APEX-seq experiments (Fazal et al. 2019) also implicated the cytoskeleton and its associated motors as being necessary for this transport, suggesting that engagement of mRNA with transport mo- 
tors and translating ribosomes can co-occur. These studies also indicate that some observed mRNA localization is a consequence of translation, as has been suggested for mitochondria in yeast (Eliyahu et al. 2010). In contrast, other RNAs were found to localize to the mitochondria independent of translation and to be preferentially coding for mitoribosome and oxidative phosphorylation proteins.

Understanding how RNAs find their destination continues to be a fascinating problem that will require imaging, sequencing, and biophysical insights. Cells rely on different approaches to transport mRNAs, and future studies will likely also focus on understanding how organelles are optimized and regulated to control the localization of transcripts to them (Tsuboi et al. 2019).

\section{Role of RNA Modifications and Structure}

RNAs are extensively modified within cells, and there exist more than a hundred types of chemical modifications (Roundtree et al. 2017a), some of which are likely to be important in specifying RNA localization. For example, the abundant epitranscriptomic modification $\mathrm{m}^{6} \mathrm{~A}$ has been shown to influence the nuclear export of RNAs, with the $\mathrm{m}^{6} \mathrm{~A}$-binding protein YTHDC1 mediating this process (Roundtree et al. 2017b). RBPs such as FMRP have been identified as $\mathrm{m}^{6} \mathrm{~A}$ readers that promote export (Edens et al. 2019), and RNA modifications are known to be involved in forming and localizing to phase-separated, membrane-less granules under stress conditions. Furthermore, $\mathrm{m}^{6} \mathrm{~A}$-modified mRNAs are enriched in stress granules (SGs), and the $\mathrm{m}^{6} \mathrm{~A}$-binding YTHDF protein is critical for SG formation (Fu and Zhuang 2019; Ries et al. 2019). Likewise, changes in the poly(A)-tail length at the end of $3^{\prime}$ UTRs have been implicated with RNA-localization changes (Fazal et al. 2019). Thus, although evidence for widespread involvement of modifications in RNA localization remains limited, these multiple observations in different systems warrant future investigation.

In addition to RNA modification, the secondary and tertiary structures of RNAs undoubtedly guide RNA localization patterns. RNA structure within cells varies across different cellular locations (Sun et al. 2019), and many RBPs such as Staufen interact with structural elements in RNAs (Bevilacqua et al. 2016). Furthermore, structured RNAs (Langdon et al. 2018; Maharana et al. 2018) in different subcellular locations show different propensities for forming liquid-liquid phase-separated condensates and organelles, including nuclear speckles, paraspeckles, Cajal bodies, nuclear stress bodies, and even heterochromatin (Sanulli et al. 2019). Thus structure-mapping studies should complement localization studies in identifying cis elements directing RNA localization.

\section{How RNAs Influence the Genome Architecture}

Genomic DNA is highly organized in three-dimensional space, and RNA has long been known to be an essential regulator of chromatin (Nickerson et al. 1989). RNA binding seems to promote CTCF-dependent chromatin looping and thus is vital for the organization of the genome into megabase structures called topologically associated domains (TADs) (Saldaña-Meyer et al. 2019). Furthermore, RNAse treatment to degrade RNAs, as well as transcriptional inhibition, affects both the structure and formation of DNA TADS (Barutcu et al. 2019). Likewise, disruption of the RNA-binding domain of CTCF, including through mutations (Hansen et al. 2019), has a global effect on chromatin binding, gene expression, and the formation of chromatin loops. However, the exact identity of RNAs in each genomic neighborhood within the nucleus that modulates the underlying processes of transcription, splicing, and genome organization remains unclear. A recently developed technology to perform RNA-directed chromosome conformation may aid in solving this mystery (Mumbach et al. 2019).

Recent studies suggest RNAs can act as structural scaffolds for organizing chromatin domains, including the lncRNA Firre that maintains the H3K27m3 chromatin state of the inactive $\mathrm{X}$ chromosome in female cells and makes contact with several autosomes (Thakur et al. 2019). Other RNAs such as MALAT1 and NEAT1 have also been shown to have scaffolding roles within the nucleus, particularly within the nuclear speckles and paraspeckles respectively. Another RNA Xist, required for transcriptional silencing of the $\mathrm{X}$ chromosome, is brought to the nuclear lamina as part of its function (Chen et al. 2016).

APEX-seq in the nucleus revealed a correlation between the location of mature, polyadenylated transcripts, and the underlying genome architecture (Fazal et al. 2019). For example, the lamina transcriptome was found to be enriched for genes found in lamina-associated domains (LADs), and the nucleolus transcriptome is enriched for genes found in nucleolus-associated domains (NADs). LADs, DNA regions near the lamina, comprise 30\%$40 \%$ of the genome and contain thousands of genes that are generally lowly expressed. In summary, there seems to be an intimate connection between subnuclear RNA localization and the underlying genome organization and regulation that warrants further investigation.

\section{How RNAs Localize to Organelles}

How cells orchestrate the localization of hundreds of RNAs to a subcellular location continues to remain a mystery. Locales such as the ERM and OMM are known to have more than a thousand transcripts localizing there. Recently, APEX-seq (Fazal et al. 2019) revealed the landscape of RNA localization and local translation to the outside of the mitochondria, identifying both translationdependent and translation-independent mechanisms of RNA localization. For reasons not clear, the translationindependent transcripts had shorter 3' UTRs and shorter poly(A)-tail lengths. Similarly, the RBP CLUH is known to bind a subset of mRNAs for nuclear-encoded mitochondrial proteins in mammals (Gao et al. 2014). Nonetheless, the localization mechanism of transcripts to the mammalian mitochondria remains opaque and will undoubtedly be an active area of future investigation.

In yeast, where RNA localization to the mitochondria is better understood, it has been speculated that the mito- 
chondrial proteins translated near the mitochondria are of prokaryotic origin, whereas accessory proteins are often translated in free cytoplasmic polysomes (Garcia et al. 2007; Marc et al. 2002). Furthermore, although the localization of proteins to the mitochondria is aided by specific amino acids in the translated nascent peptide, called mitochondria-targeting sequences (MTSs), sequences in the 3' UTR of the corresponding RNA have also been shown to be essential for local translation. For example, in yeast, either the MTS or the 3' UTR was sufficient to independently target ATM1 mRNA to the vicinity of the mitochondria (Corral-Debrinski et al. 2000). Also, some RBPs such as the Puf family of proteins in yeast control the localization of hundreds of transcripts, particularly Puf3 that associates with transcripts encoding proteins localizing to the mitochondria (Hogan et al. 2008).

In addition to the ER and mitochondria, many locations in cells concentrate RNAs, including MLOs present in both the nucleus and cytosol. Interestingly, the MLOs' nucleolus and stress bodies are known to phase separate and are tuned and regulated by the concentration of proteins and RNAs within them. Furthermore, long RNAs with stable secondary structures that bind RNA binding proteins are particularly good at promoting phase separation, including in nuclear locations such as paraspeckles. Understanding how RNAs are specifically targeted to MLOs and membrane-bound organelles continues to be a fascinating, unanswered question.

\section{How Nonpolyadenylated RNAs, including Circular RNAs, Localize within Cells}

Cells contain many different RNA species, and extending our current understanding of mRNA localization to other RNA species, including tRNAs and circular RNAs (circRNAs), will be important in understanding the regulation of these molecules. circRNAs have received a lot of interest in recent years, and it is known that they can code for proteins (Jeck and Sharpless 2014) and show asymmetric subcellular localization (Saini et al. 2019). Initial studies, for example, suggest circRNAs localize differently relative to other RNAs in neuronal projections (Saini et al. 2019). In addition, immunogenic circRNAs that are sensed as foreign are localized to distinct locations in the cytoplasm compared to endogenous circRNAs (Chen et al. 2019b). Thus, the mechanisms of circRNA localization, often without the benefit of 5' or 3' UTRs present on linear mRNAs, are likely to shed new light on RNA localization and circRNA functions.

\section{CONCLUSION}

Subcellular RNA localization is an essential but underappreciated aspect of gene regulation. This review focuses on the eukaryotic cell, but even prokaryotic cells are known to have highly localized RNAs (Nevo-Dinur et al. 2011). In prokaryotes, RNAs are directed to specific locations such as the inner membrane, although whether this localization is exclusively translation-dependent or not remains an open question (Moffitt et al. 2016). With the advent of high-throughput imaging and sequencing approaches, it is now possible to comprehensive interrogate the transcriptomes of subcellular locations in different cell types and model systems. Exciting future studies will undoubtedly map out the regulatory code guiding localization, and explain why organisms ubiquitously use such mechanisms.

\section{ACKNOWLEDGMENTS}

F.M.F. acknowledges funding from the Arnold O. Beckman postdoctoral fellowship, and by a National Institutes of Health (NIH) K99/R00 award from the National Human Genome Research Institute (NHGRI) (HG010910). H.Y.C. is supported by RM1-HG007735, R35-CA209919, and R01-HG004361. H.Y.C. is an Investigator of the Howard Hughes Medical Institute. We apologize to colleagues for the exclusion of references because of space constraints. Some figures were created with BioRender as part of an academic license.

\section{REFERENCES}

Alami NH, Smith RB, Carrasco MA, Williams LA, Winborn CS, Han SSW, Kiskinis E, Winborn B, Freibaum BD, Kanagaraj A, et al. 2014. Axonal transport of TDP-43 mRNA granules is impaired by ALS-causing mutations. Neuron 81: 536-543. doi:10.1016/j.neuron.2013.12.018

Anderson P, Kedersha N. 2006. RNA granules. J Cell Biol 172: 803-808. doi:10.1083/jcb.200512082

Bahar Halpern K, Caspi I, Lemze D, Levy M, Landen S, Elinav E, Ulitsky I, Itzkovitz S. 2015. Nuclear retention of mRNA in mammalian tissues. Cell Rep 13: 2653-2662. doi:10.1016/j .celrep.2015.11.036

Barutcu AR, Blencowe BJ, Rinn JL. 2019. Differential contribution of steady-state RNA and active transcription in chromatin organization. EMBO Rep 20: e48068. doi:10.15252/embr .201948068

Batista PJ, Chang HY. 2013. Long noncoding RNAs: cellular address codes in development and disease. Cell 152: 1298 1307. doi:10.1016/j.cell.2013.02.012

Baumann S, Komissarov A, Gili M, Ruprecht V, Wieser S, Maurer SP. 2020. A reconstituted mammalian APC-kinesin complex selectively transports defined packages of axonal mRNAs. Sci Adv 6: eaaz1588. doi:10.1126/sciadv.aaz1588

Benhalevy D, Anastasakis DG, Hafner M. 2018. Proximity-CLIP provides a snapshot of protein-occupied RNA elements in subcellular compartments. Nat Methods 15: 1074-1082. doi:10.1038/s41592-018-0220-y

Benoit Bouvrette LP, Cody NAL, Bergalet J, Lefebvre FA, Diot C, Wang X, Blanchette M, Lecuyer E. 2018. CeFra-seq reveals broad asymmetric mRNA and noncoding RNA distribution profiles in Drosophila and human cells. RNA 24: 98-113. doi:10.1261/rna.063172.117

Bertrand E, Chartrand P, Schaefer M, Shenoy SM, Singer RH, Long RM. 1998. Localization of ASH1 mRNA particles in living yeast. Mol Cell 2: 437-445. doi:10.1016/S1097-2765 (00)80143-4

Bevilacqua PC, Ritchey LE, Su Z, Assmann SM. 2016. Genomewide analysis of RNA secondary structure. Annu Rev Genet 50: 235-266. doi:10.1146/annurev-genet-120215-035034

Braselmann E, Wierzba AJ, Polaski JT, Chrominski M, Holmes ZE, Hung ST, Batan D, Wheeler JR, Parker R, Jimenez R, et al. 2018. A multicolor riboswitch-based platform for imaging of RNA in live mammalian cells. Nat Chem Biol 14: 964-971. doi:10.1038/s41589-018-0103-7 
Braunschweig U, Gueroussov S, Plocik AM, Graveley BR, Blencowe BJ. 2013. Dynamic integration of splicing within gene regulatory pathways. Cell 152: 1252-1269. doi:10.1016/j.cell .2013 .02 .034

Braunschweig U, Barbosa-Morais NL, Pan Q, Nachman EN, Alipanahi B, Gonatopoulos-Pournatzis T, Frey B, Irimia M, Blencowe BJ. 2014. Widespread intron retention in mammals functionally tunes transcriptomes. Genome Res 24: 17741786. doi:10.1101/gr.177790.114

Brown CR, Silver PA. 2007. Transcriptional regulation at the nuclear pore complex. Curr Opin Genet Dev 17: 100-106. doi:10.1016/j.gde.2007.02.005

Cajigas IJ, Tushev G, Will TJ, tom Dieck S, Fuerst N, Schuman EM. 2012. The local transcriptome in the synaptic neuropil revealed by deep sequencing and high-resolution imaging. Neuron 74: 453-466. doi:10.1016/j.neuron.2012.02.036

Cao Z, Pan X, Yang Y, Huang Y, Shen HB. 2018. The lncLocator: a subcellular localization predictor for long non-coding RNAs based on a stacked ensemble classifier. Bioinformatics 34: 2185-2194. doi:10.1093/bioinformatics/bty085

Carlevaro-Fita J, Polidori T, Das M, Navarro C, Zoller TI, Johnson R. 2019. Ancient exapted transposable elements promote nuclear enrichment of human long noncoding RNAs. Genome Res 29: 208-222. doi:10.1101/gr.229922.117

Chaumeil J, Le Baccon P, Wutz A, Heard E. 2006. A novel role for Xist RNA in the formation of a repressive nuclear compartment into which genes are recruited when silenced. Genes Dev 20: 2223-2237. doi:10.1101/gad.380906

Chen KH, Boettiger AN, Moffitt JR, Wang S, Zhuang X. 2015. RNA imaging. Spatially resolved, highly multiplexed RNA profiling in single cells. Science 348: aaa6090. doi:10.1126/ science.aaa6090

Chen CK, Blanco M, Jackson C, Aznauryan E, Ollikainen N, Surka C, Chow A, Cerase A, McDonel P, Guttman M. 2016. Xist recruits the $\mathrm{X}$ chromosome to the nuclear lamina to enable chromosome-wide silencing. Science 354: 468-472. doi:10 $.1126 /$ science.aae 0047

Chen M, Ma Z, Wu X, Mao S, Yang Y, Tan J, Krueger CJ, Chen AK. 2017. A molecular beacon-based approach for live-cell imaging of RNA transcripts with minimal target engineering at the single-molecule level. Sci Rep 7: 1550. doi:10.1038/ s41598-017-01740-1

Chen K, Wang Y, Sun J. 2018. A statistical analysis on transcriptome sequences: the enrichment of Alu-element is associated with subcellular location. Biochem Biophys Res Commun 499: 397-402. doi:10.1016/j.bbrc.2018.03.024

Chen X, Zhang D, Su N, Bao B, Xie X, Zuo F, Yang L, Wang H, Jiang L, Lin Q, et al. 2019a. Visualizing RNA dynamics in live cells with bright and stable fluorescent RNAs. Nat Biotechnol 37: 1287-1293. doi:10.1038/s41587-019-0249-1

Chen YG, Chen R, Ahmad S, Verma R, Kasturi SP, Amaya L, Broughton JP, Kim J, Cadena C, Pulendran B, et al. 2019b. N6' methyladenosine modification controls circular RNA immunity. Mol Cell 76: 96-109 e109. doi:10.1016/j.molcel.2019.07 .016

Cheng H, Dufu K, Lee CS, Hsu JL, Dias A, Reed R. 2006. Human mRNA export machinery recruited to the $5^{\prime}$ end of mRNA. Cell 127: 1389-1400. doi:10.1016/j.cell.2006.10.044

Chu C, Zhang QC, da Rocha ST, Flynn RA, Bharadwaj M, Calabrese JM, Magnuson T, Heard E, Chang HY. 2015. Systematic discovery of Xist RNA binding proteins. Cell 161: 404-416. doi:10.1016/j.cell.2015.03.025

Ciolli Mattioli C, Rom A, Franke V, Imami K, Arrey G, Terne M, Woehler A, Akalin A, Ulitsky I, Chekulaeva M. 2019. Alternative $3^{\prime}$ UTRs direct localization of functionally diverse protein isoforms in neuronal compartments. Nucleic Acids Res 47: 2560-2573. doi:10.1093/nar/gky1270

Cohen-Zontag O, Baez C, Lim LQJ, Olender T, Schirman D, Dahary D, Pilpel Y, Gerst JE. 2019. A secretion-enhancing cis regulatory targeting element (SECReTE) involved in mRNA localization and protein synthesis. PLoS Genet 15: e1008248. doi:10.1371/journal.pgen.1008248
Colon-Ramos DA, Salisbury JL, Sanders MA, Shenoy SM, Singer RH, Garcia-Blanco MA. 2003. Asymmetric distribution of nuclear pore complexes and the cytoplasmic localization of $\beta 2$-tubulin mRNA in Chlamydomonas reinhardtii. Dev Cell 4: 941-952. doi:10.1016/S1534-5807(03)00163-1

Corral-Debrinski M, Blugeon C, Jacq C. 2000. In yeast, the 3' untranslated region or the presequence of ATM1 is required for the exclusive localization of its mRNA to the vicinity of mitochondria. Mol Cell Biol 20: 7881-7892. doi:10.1128/MCB .20.21.7881-7892.2000

Costa EA, Subramanian K, Nunnari J, Weissman JS. 2018. Defining the physiological role of SRP in protein-targeting efficiency and specificity. Science 359: 689-692. doi:10.1126/ science.aar3607

Darzacq X, Shav-Tal Y, de Turris V, Brody Y, Shenoy SM, Phair RD, Singer RH. 2007. In vivo dynamics of RNA polymerase II transcription. Nat Struct Mol Biol 14: 796-806. doi:10.1038/ nsmb1280

de Boer CG, Vaishnav ED, Sadeh R, Abeyta EL, Friedman N, Regev A. 2019. Deciphering eukaryotic gene-regulatory logic with 100 million random promoters. Nat Biotechnol 38: 5665. doi:10.1038/s41587-019-0315-8

Djebali S, Davis CA, Merkel A, Dobin A, Lassmann T, Mortazavi A, Tanzer A, Lagarde J, Lin W, Schlesinger F, et al. 2012. Landscape of transcription in human cells. Nature 489: 101108. doi:10.1038/nature11233

Edens BM, Vissers C, Su J, Arumugam S, Xu Z, Shi H, Miller N, Rojas Ringeling F, Ming GL, He C, et al. 2019. FMRP modulates neural differentiation through $\mathrm{m}^{6} \mathrm{~A}$-dependent mRNA nuclear export. Cell Rep 28: 845-854 e845. doi:10.1016/j .celrep.2019.06.072

Eliyahu E, Pnueli L, Melamed D, Scherrer T, Gerber AP, Pines O, Rapaport D, Arava Y. 2010. Tom20 mediates localization of mRNAs to mitochondria in a translation-dependent manner. Mol Cell Biol 30: 284-294. doi:10.1128/MCB.00651-09

Emanuel G, Moffitt JR, Zhuang X. 2017. High-throughput, image-based screening of pooled genetic-variant libraries. Nat Methods 14: 1159-1162. doi:10.1038/nmeth.4495

Eng CL, Lawson M, Zhu Q, Dries R, Koulena N, Takei Y, Yun J, Cronin C, Karp C, Yuan GC, et al. 2019. Transcriptome-scale super-resolved imaging in tissues by RNA seqFISH. Nature 568: 235-239. doi:10.1038/s41586-019-1049-y

Erdelyi M, Michon AM, Guichet A, Glotzer JB, Ephrussi A. 1995. Requirement for Drosophila cytoplasmic tropomyosin in oskar mRNA localization. Nature 377: 524-527. doi:10 $.1038 / 377524 \mathrm{a} 0$

Fazal FM, Han S, Parker KR, Kaewsapsak P, Xu J, Boettiger AN, Chang HY, Ting AY. 2019. Atlas of subcellular RNA localization revealed by APEX-seq. Cell 178: 473-490 e426. doi:10 $.1016 /$ j.cell.2019.05.027

Femino AM, Fay FS, Fogarty K, Singer RH. 1998. Visualization of single RNA transcripts in situ. Science 280: 585-590. doi:10.1126/science.280.5363.585

Fu Y, Zhuang X. 2019. m6A-binding YTHDF proteins promote stress granule formation by modulating phase separation of stress granule proteins. bioRxiv doi:10.1101/694455

Fürth D, Hatini V, Lee JH. 2019. In situ transcriptome accessibility sequencing (INSTA-seq). bioRxiv doi:10.1101/722819

Gadir N, Haim-Vilmovsky L, Kraut-Cohen J, Gerst JE. 2011. Localization of mRNAs coding for mitochondrial proteins in the yeast Saccharomyces cerevisiae. RNA 17: 1551-1565. doi:10.1261/rna.2621111

Gao J, Schatton D, Martinelli P, Hansen H, Pla-Martin D, Barth E, Becker C, Altmueller J, Frommolt P, Sardiello M, et al. 2014. CLUH regulates mitochondrial biogenesis by binding mRNAs of nuclear-encoded mitochondrial proteins. J Cell Biol 207: 213-223. doi:10.1083/jcb.201403129

Gao XD, Tu LC, Mir A, Rodriguez T, Ding Y, Leszyk J, Dekker J, Shaffer SA, Zhu LJ, Wolfe SA, et al. 2018. C-BERST: defining subnuclear proteomic landscapes at genomic elements with dCas9-APEX2. Nat Methods 15: 433-436. doi:10 .1038/s41592-018-0006-2 
Garalde DR, Snell EA, Jachimowicz D, Sipos B, Lloyd JH, Bruce M, Pantic N, Admassu T, James P, Warland A, et al. 2018. Highly parallel direct RNA sequencing on an array of nanopores. Nat Methods 15: 201-206. doi:10.1038/nmeth .4577

Garcia M, Darzacq X, Delaveau T, Jourdren L, Singer RH, Jacq C. 2007. Mitochondria-associated yeast mRNAs and the biogenesis of molecular complexes. Mol Biol Cell 18: 362-368. doi:10.1091/mbc.e06-09-0827

Ghosh S, Marchand V, Gaspar I, Ephrussi A. 2012. Control of RNP motility and localization by a splicing-dependent structure in oskar mRNA. Nat Struct Mol Biol 19: 441-449. doi:10 $.1038 / \mathrm{nsmb} .2257$

Grunwald D, Singer RH. 2010. In vivo imaging of labelled endogenous $\beta$-actin mRNA during nucleocytoplasmic transport. Nature 467: 604-607. doi:10.1038/nature09438

Gudenas BL, Wang L. 2018. Prediction of LncRNA subcellular localization with deep learning from sequence features. $\mathrm{Scl}$ Rep 8: 16385. doi:10.1038/s41598-018-34708-w

Hachet O, Ephrussi A. 2004. Splicing of oskar RNA in the nucleus is coupled to its cytoplasmic localization. Nature 428: 959-963. doi:10.1038/nature02521

Hacisuleyman E, Goff LA, Trapnell C, Williams A, Henao-Mejia J, Sun L, McClanahan P, Hendrickson DG, Sauvageau M, Kelley DR, et al. 2014. Topological organization of multichromosomal regions by the long intergenic noncoding RNA Firre. Nat Struct Mol Biol 21: 198-206. doi:10.1038/nsmb .2764

Han S, Zhao BS, Myers SA, Carr SA, He C, Ting AY. 2020. RNA-protein interaction mapping via MS2 or Cas13-based APEX targeting. bioRxiv doi:10.1101/968297

Hancock WO. 2014. Bidirectional cargo transport: moving beyond tug of war. Nat Rev Mol Cell Biol 15: 615-628. doi:10 .1038/nrm3853

Hansen AS, Hsieh TS, Cattoglio C, Pustova I, Saldaña-Meyer R, Reinberg D, Darzacq X, Tjian R. 2019. Distinct classes of chromatin loops revealed by deletion of an RNA-binding region in CTCF. Mol Cell 76: 395-411 e313. doi:10.1016/j .molcel.2019.07.039

Hasegawa Y, Brockdorff N, Kawano S, Tsutui K, Tsutui K, Nakagawa S. 2010. The matrix protein hnRNP U is required for chromosomal localization of Xist RNA. Dev Cell 19: 469476. doi:10.1016/j.devcel.2010.08.006

Hirokawa N, Niwa S, Tanaka Y. 2010. Molecular motors in neurons: transport mechanisms and roles in brain function, development, and disease. Neuron 68: 610-638. doi:10.1016/j .neuron.2010.09.039

Hogan DJ, Riordan DP, Gerber AP, Herschlag D, Brown PO. 2008. Diverse RNA-binding proteins interact with functionally related sets of RNAs, suggesting an extensive regulatory system. PLoS Biol 6: e255. doi:10.1371/journal.pbio.0060255

Hung V, Udeshi ND, Lam SS, Loh KH, Cox KJ, Pedram K, Carr SA, Ting AY. 2016. Spatially resolved proteomic mapping in living cells with the engineered peroxidase APEX2. Nat Protoc 11: 456-475. doi:10.1038/nprot.2016.018

Huttelmaier S, Zenklusen D, Lederer M, Dictenberg J, Lorenz M, Meng X, Bassell GJ, Condeelis J, Singer RH. 2005. Spatial regulation of $\beta$-actin translation by Src-dependent phosphorylation of ZBP1. Nature 438: 512-515. doi:10.1038/ nature 04115

Hwang HW, Wentzel EA, Mendell JT. 2007. A hexanucleotide element directs microRNA nuclear import. Science 315: 97 100. doi: $10.1126 /$ science. 1136235

Jan CH, Williams CC, Weissman JS. 2014. Principles of ER cotranslational translocation revealed by proximity-specific ribosome profiling. Science 346: 1257521. doi:10.1126/science .1257521

Jeck WR, Sharpless NE. 2014. Detecting and characterizing circular RNAs. Nat Biotechnol 32: 453-461. doi:10.1038/nbt .2890

Kaewsapsak P, Shechner DM, Mallard W, Rinn JL, Ting AY. 2017. Live-cell mapping of organelle-associated RNAs via proximity biotinylation combined with protein-RNA crosslinking. Elife 6: e29224. doi:10.7554/eLife.29224

Kanai Y, Dohmae N, Hirokawa N. 2004. Kinesin transports RNA: isolation and characterization of an RNA-transporting granule. Neuron 43: 513-525. doi:10.1016/j.neuron.2004.07 .022

Katahira J. 2015. Nuclear export of messenger RNA. Genes (Basel) 6: 163-184. doi:10.3390/genes6020163

Ke R, Mignardi M, Pacureanu A, Svedlund J, Botling J, Wahlby C, Nilsson M. 2013. In situ sequencing for RNA analysis in preserved tissue and cells. Nat Methods 10: $857-860$. doi:10 1038/nmeth.2563

Khong A, Matheny T, Jain S, Mitchell SF, Wheeler JR, Parker R. 2017. The stress granule transcriptome reveals principles of mRNA accumulation in stress granules. Mol Cell 68: 808-820 e805. doi:10.1016/j.molcel.2017.10.015

Kim-Ha J, Webster PJ, Smith JL, Macdonald PM. 1993. Multiple RNA regulatory elements mediate distinct steps in localization of oskar mRNA. Development 119: 169-178.

Kislauskis EH, Zhu X, Singer RH. 1994. Sequences responsible for intracellular localization of $\beta$-actin messenger RNA also affect cell phenotype. J Cell Biol 127: 441-451. doi:10.1083/ jcb.127.2.441

Krauss J, Lopez de Quinto S, Nusslein-Volhard C, Ephrussi A. 2009. Myosin-V regulates oskar mRNA localization in the Drosophila oocyte. Curr Biol 19: 1058-1063. doi:10.1016/j .cub.2009.04.062

Langdon EM, Qiu Y, Ghanbari Niaki A, McLaughlin GA, Weidmann CA, Gerbich TM, Smith JA, Crutchley JM, Termini CM, Weeks KM, et al. 2018. mRNA structure determines specificity of a polyQ-driven phase separation. Science 360: 922-927. doi:10.1126/science.aar7432

Lawrence JB, Singer RH, Marselle LM. 1989. Highly localized tracks of specific transcripts within interphase nuclei visualized by in situ hybridization. Cell 57: 493-502. doi:10.1016/ 0092-8674(89)90924-0

LeCun Y, Bengio Y, Hinton G. 2015. Deep learning. Nature 521: 436-444. doi:10.1038/nature14539

Lee JH, Daugharthy ER, Scheiman J, Kalhor R, Yang JL, Ferrante TC, Terry R, Jeanty SS, Li C, Amamoto R, et al. 2014. Highly multiplexed subcellular RNA sequencing in situ. Science 343: 1360-1363. doi:10.1126/science.1250212

Legnini I, Alles J, Karaiskos N, Ayoub S, Rajewsky N. 2019. FLAM-seq: full-length mRNA sequencing reveals principles of poly(A) tail length control. Nat Methods 16: 879-886. doi:10.1038/s41592-019-0503-y

Lesbirel S, Wilson SA. 2019. The $\mathrm{m}^{6} \mathrm{~A}$ methylase complex and mRNA export. Biochim Biophys Acta 1862: 319-328. doi:10 .1016/j.bbagrm.2018.09.008

Li Y, Aggarwal MB, Nguyen K, Ke K, Spitale RC. 2017. Assaying RNA localization in situ with spatially restricted nucleobase oxidation. ACS Chem Biol 12: 2709-2714. doi:10.1021/ acschembio.7b00519

Lubeck E, Coskun AF, Zhiyentayev T, Ahmad M, Cai L. 2014. Single-cell in situ RNA profiling by sequential hybridization. Nat Methods 11: 360-361. doi:10.1038/nmeth.2892

Lubelsky Y, Ulitsky I. 2018. Sequences enriched in Alu repeats drive nuclear localization of long RNAs in human cells. $\mathrm{Na}$ ture 555: 107-111. doi:10.1038/nature25757

Ma J, Liu Z, Michelotti N, Pitchiaya S, Veerapaneni R, Androsavich JR, Walter NG, Yang W. 2013. High-resolution threedimensional mapping of mRNA export through the nuclear pore. Nat Commun 4: 2414. doi:10.1038/ncomms3414

Maday S, Twelvetrees AE, Moughamian AJ, Holzbaur EL. 2014. Axonal transport: cargo-specific mechanisms of motility and regulation. Neuron 84: 292-309. doi:10.1016/j.neuron.2014 .10 .019

Maharana S, Wang J, Papadopoulos DK, Richter D, Pozniakovsky A, Poser I, Bickle M, Rizk S, Guillen-Boixet J, Franzmann TM, et al. 2018. RNA buffers the phase separation behavior of prion-like RNA binding proteins. Science 360: 918-921. doi:10.1126/science.aar7366 
Marc P, Margeot A, Devaux F, Blugeon C, Corral-Debrinski M, Jacq C. 2002. Genome-wide analysis of mRNAs targeted to yeast mitochondria. EMBO Rep 3: 159-164. doi:10.1093/ embo-reports/kvf025

Markmiller S, Soltanieh S, Server KL, Mak R, Jin W, Fang MY, Luo EC, Krach F, Yang D, Sen A, et al. 2018. Context-dependent and disease-specific diversity in protein interactions within stress granules. Cell 172: 590-604 e513. doi:10.1016/j.cell 2017.12.032

Medina-Muñoz HC, Lapointe CP, Porter DF, Wickens M. 2019. Records of RNA localization through covalent tagging. bioRxiv doi:10.1101/785816

Mili S, Moissoglu K, Macara IG. 2008. Genome-wide screen reveals APC-associated RNAs enriched in cell protrusions. Nature 453: 115-119. doi:10.1038/nature06888

Miyagawa R, Tano K, Mizuno R, Nakamura Y, Ijiri K, Rakwal R, Shibato J, Masuo Y, Mayeda A, Hirose T, et al. 2012. Identification of cis-and trans-acting factors involved in the localization of MALAT-1 noncoding RNA to nuclear speckles. RNA 18: 738-751. doi:10.1261/rna.028639.111

Moffitt JR, Pandey S, Boettiger AN, Wang S, Zhuang X. 2016. Spatial organization shapes the turnover of a bacterial transcriptome. Elife 5: e13065. doi:10.7554/eLife.13065

Moffitt JR, Bambah-Mukku D, Eichhorn SW, Vaughn E, Shekhar K, Perez JD, Rubinstein ND, Hao J, Regev A, Dulac C, et al. 2018. Molecular, spatial, and functional single-cell profiling of the hypothalamic preoptic region. Science 362: eaau5324. doi:10.1126/science.aau5324

Moon SL, Morisaki T, Khong A, Lyon K, Parker R, Stasevich TJ. 2019. Multicolour single-molecule tracking of mRNA interactions with RNP granules. Nat Cell Biol 21: 162-168. doi:10 .1038/s41556-018-0263-4

Moor AE, Golan M, Massasa EE, Lemze D, Weizman T, Shenhav R, Baydatch S, Mizrahi O, Winkler R, Golani O, et al. 2017. Global mRNA polarization regulates translation efficiency in the intestinal epithelium. Science 357: 1299-1303. doi:10.1126/science.aan2399

Movva R, Greenside P, Marinov GK, Nair S, Shrikumar A, Kundaje A. 2019. Deciphering regulatory DNA sequences and noncoding genetic variants using neural network models of massively parallel reporter assays. PLoS One 14: e0218073. doi:10.1371/journal.pone.0218073

Mukherjee J, Hermesh O, Eliscovich C, Nalpas N, Franz-Wachtel M, Macek B, Jansen RP. 2019. $\beta$-Actin mRNA interactome mapping by proximity biotinylation. Proc Natl Acad Sci 116: 12863-12872. doi:10.1073/pnas.1820737116

Muller-McNicoll M, Neugebauer KM. 2013. How cells get the message: dynamic assembly and function of mRNA-protein complexes. Nat Rev Genet 14: 275-287. doi:10.1038/nrg3434

Mumbach MR, Granja JM, Flynn RA, Roake CM, Satpathy AT, Rubin AJ, Qi Y, Jiang Z, Shams S, Louie BH, et al. 2019. HiChIRP reveals RNA-associated chromosome conformation. Nat Methods 16: 489-492. doi:10.1038/s41592-019-0407-x

Myers SA, Wright J, Peckner R, Kalish BT, Zhang F, Carr SA. 2018. Discovery of proteins associated with a predefined genomic locus via dCas9-APEX-mediated proximity labeling. Nat Methods 15: 437-439. doi:10.1038/s41592-018-0007-1

Nelles DA, Fang MY, O’Connell MR, Xu JL, Markmiller SJ, Doudna JA, Yeo GW. 2016. Programmable RNA tracking in live cells with CRISPR/Cas9. Cell 165: 488-496. doi:10 .1016/j.cell.2016.02.054

Neumann M, Sampathu DM, Kwong LK, Truax AC, Micsenyi MC, Chou TT, Bruce J, Schuck T, Grossman M, Clark CM, et al. 2006. Ubiquitinated TDP-43 in frontotemporal lobar degeneration and amyotrophic lateral sclerosis. Science 314: 130-133. doi:10.1126/science. 1134108

Nevo-Dinur K, Nussbaum-Shochat A, Ben-Yehuda S, AmsterChoder O. 2011. Translation-independent localization of mRNA in E. coli. Science 331: 1081-1084. doi:10.1126/sci ence.1195691

Nguyen TM, Kabotyanski EB, Reineke LC, Shao J, Xiong F, Lee JH, Dubrulle J, Johnson H, Stossi F, Tsoi PS, et al. 2020. The SINEB1 element in the long non-coding RNA Malat1 is nec- essary for TDP-43 proteostasis. Nucleic Acids Res 48: 26212642. doi:10.1093/nar/gkz1176

Nichterwitz S, Chen G, Aguila Benitez J, Yilmaz M, Storvall H, Cao M, Sandberg R, Deng Q, Hedlund E. 2016. Laser capture microscopy coupled with Smart-seq2 for precise spatial transcriptomic profiling. Nat Commun 7: 12139. doi:10.1038/ ncomms12139

Nickerson JA, Krochmalnic G, Wan KM, Penman S. 1989. Chromatin architecture and nuclear RNA. Proc Natl Acad Sci 86: 177-181. doi:10.1073/pnas.86.1.177

Padron A, Iwasaki S, Ingolia NT. 2019. Proximity RNA labeling by APEX-seq reveals the organization of translation initiation complexes and repressive RNA granules. Mol Cell 75: 875887 e875. doi:10.1016/j.molcel.2019.07.030

Pyhtila B, Zheng T, Lager PJ, Keene JD, Reedy MC, Nicchitta CV. 2008. Signal sequence- and translation-independent mRNA localization to the endoplasmic reticulum. RNA 14: 445-453. doi:10.1261/rna.721108

Qiu W, Xu Z, Zhang M, Zhang D, Fan H, Li T, Wang Q, Liu P, Zhu Z, Du D, et al. 2019. Determination of local chromatin interactions using a combined CRISPR and peroxidase APEX2 system. Nucleic Acids Res 47: e52. doi:10.1093/nar/ gkz134

Raj A, van den Bogaard P, Rifkin SA, van Oudenaarden A, Tyagi S. 2008. Imaging individual mRNA molecules using multiple singly labeled probes. Nat Methods 5: 877-879. doi:10.1038/ nmeth. 1253

Ramanathan M, Majzoub K, Rao DS, Neela PH, Zarnegar BJ, Mondal S, Roth JG, Gai H, Kovalski JR, Siprashvili Z, et al. 2018. RNA-protein interaction detection in living cells. Nat Methods 15: 207-212. doi:10.1038/nmeth.4601

Ramanathan M, Porter DF, Khavari PA. 2019. Methods to study RNA-protein interactions. Nat Methods 16: 225-234. doi:10 .1038/s41592-019-0330-1

Rebagliati MR, Weeks DL, Harvey RP, Melton DA. 1985. Identification and cloning of localized maternal RNAs from Xenopus eggs. Cell 42: 769-777. doi:10.1016/0092-8674(85) 90273-9

Rhee HW, Zou P, Udeshi ND, Martell JD, Mootha VK, Carr SA, Ting AY. 2013. Proteomic mapping of mitochondria in living cells via spatially restricted enzymatic tagging. Science 339: 1328-1331. doi:10.1126/science.1230593

Ries RJ, Zaccara S, Klein P, Olarerin-George A, Namkoong S, Pickering BF, Patil DP, Kwak H, Lee JH, Jaffrey SR. 2019. $\mathrm{m}(6) \mathrm{A}$ enhances the phase separation potential of mRNA. Nature 571: 424-428. doi:10.1038/s41586-019-1374-1

Roundtree IA, Evans ME, Pan T, He C. 2017a. Dynamic RNA modifications in gene expression regulation. Cell 169: 11871200. doi:10.1016/j.cell.2017.05.045

Roundtree IA, Luo GZ, Zhang Z, Wang X, Zhou T, Cui Y, Sha J, Huang X, Guerrero L, Xie P, et al. 2017b. YTHDC1 mediates nuclear export of $N^{6}$-methyladenosine methylated mRNAs. Elife 6: e31311. doi:10.7554/eLife.31311

Roux KJ, Kim DI, Raida M, Burke B. 2012. A promiscuous biotin ligase fusion protein identifies proximal and interacting proteins in mammalian cells. J Cell Biol 196: $801-810$. doi: 10 $.1083 /$ jcb.201112098

Saini H, Bicknell AA, Eddy SR, Moore MJ. 2019. Free circular introns with an unusual branchpoint in neuronal projections. Elife 8: e47809. doi:10.7554/eLife.47809

Saint-Georges Y, Garcia M, Delaveau T, Jourdren L, Le Crom S, Lemoine S, Tanty V, Devaux F, Jacq C. 2008. Yeast mitochondrial biogenesis: a role for the PUF RNA-binding protein Puf3p in mRNA localization. PLoS One 3: e2293. doi:10 .1371 /journal.pone.0002293

Saldaña-Meyer R, Rodriguez-Hernaez J, Escobar T, Nishana M, Jacome-Lopez K, Nora EP, Bruneau BG, Tsirigos A, FurlanMagaril M, Skok J, et al. 2019. RNA interactions are essential for CTCF-mediated genome organization. Mol Cell 76: 412422 e415. doi:10.1016/j.molcel.2019.08.015

Sanulli S, Trnka MJ, Dharmarajan V, Tibble RW, Pascal BD, Burlingame AL, Griffin PR, Gross JD, Narlikar GJ. 2019. HP1 reshapes nucleosome core to promote phase separation 
of heterochromatin. Nature 575: 390-394. doi:10.1038/ s41586-019-1669-2

Shah S, Lubeck E, Zhou W, Cai L. 2016. In situ transcription profiling of single cells reveals spatial organization of cells in the mouse hippocampus. Neuron 92: 342-357. doi:10.1016/j .neuron.2016.10.001

Shah S, Takei Y, Zhou W, Lubeck E, Yun J, Eng CL, Koulena N, Cronin C, Karp C, Liaw EJ, et al. 2018. Dynamics and spatial genomics of the nascent transcriptome by intron seqFISH. Cell 174: 363-376 e316. doi:10.1016/j.cell.2018.05.035

Siebrasse JP, Kaminski T, Kubitscheck U. 2012. Nuclear export of single native mRNA molecules observed by light sheet fluorescence microscopy. Proc Natl Acad Sci 109: 94269431. doi:10.1073/pnas.1201781109

Soneson C, Yao Y, Bratus-Neuenschwander A, Patrignani A, Robinson MD, Hussain S. 2019. A comprehensive examination of Nanopore native RNA sequencing for characterization of complex transcriptomes. Nat Commun 10: 3359. doi:10 .1038/s41467-019-11272-z

Sreedharan J, Blair IP, Tripathi VB, Hu X, Vance C, Rogelj B, Ackerley S, Durnall JC, Williams KL, Buratti E, et al. 2008. TDP-43 mutations in familial and sporadic amyotrophic lateral sclerosis. Science 319: 1668-1672. doi:10.1126/science .1154584

St Johnston D, Beuchle D, Nusslein-Volhard C. 1991. Staufen, a gene required to localize maternal RNAs in the Drosophila egg. Cell 66: 51-63. doi:10.1016/0092-8674(91)90138-O

St Johnston D, Brown NH, Gall JG, Jantsch M. 1992. A conserved double-stranded RNA-binding domain. Proc Natl Acad Sci 89: 10979-10983. doi:10.1073/pnas.89.22.10979

Su ZD, Huang Y, Zhang ZY, Zhao YW, Wang D, Chen W, Chou $\mathrm{KC}$, Lin H. 2018. iLoc-lncRNA: predict the subcellular location of lncRNAs by incorporating octamer composition into general PseKNC. Bioinformatics 34: 4196-4204.

Sun L, Fazal FM, Li P, Broughton JP, Lee B, Tang L, Huang W, Kool ET, Chang HY, Zhang QC. 2019. RNA structure maps across mammalian cellular compartments. Nat Struct Mol Biol 26: 322-330. doi:10.1038/s41594-019-0200-7

Taliaferro JM, Vidaki M, Oliveira R, Olson S, Zhan L, Saxena T, Wang ET, Graveley BR, Gertler FB, Swanson MS, et al. 2016. Distal alternative last exons localize mRNAs to neural projections. Mol Cell 61: 821-833. doi:10.1016/j.molcel.2016.01 .020

Thakur J, Fang H, Llagas T, Disteche CM, Henikoff S. 2019. Architectural RNA is required for heterochromatin organization. bioRxiv doi: $10.1101 / 78435 \mathrm{v} 1$

Thul PJ, Akesson L, Wiking M, Mahdessian D, Geladaki A, Ait Blal H, Alm T, Asplund A, Björk L, Breckels LM, et al. 2017. A subcellular map of the human proteome. Science 356: eaal3321. doi:10.1126/science.aal3321

Tsuboi T, Viana MP, Xu F, Yu J, Chanchani R, Arceo XG, Tutucci E, Choi J, Chen YS, Singer RH, et al. 2019. Mitochondrial volume fraction and translation speed impact mRNA localization and production of nuclear-encoded mitochondrial proteins. bioRxiv doi:10.1101/529289

Uhlen M, Oksvold P, Fagerberg L, Lundberg E, Jonasson K, Forsberg M, Zwahlen M, Kampf C, Wester K, Hober S, et al. 2010. Towards a knowledge-based Human Protein Atlas. Nat Biotechnol 28: 1248-1250. doi:10.1038/nbt1210-1248

Uhlen M, Fagerberg L, Hallstrom BM, Lindskog C, Oksvold P, Mardinoglu A, Sivertsson A, Kampf C, Sjostedt E, Asplund A, et al. 2015. Proteomics. Tissue-based map of the human proteome. Science 347: 1260419. doi:10.1126/science.1260419

Van Nostrand EL, Pratt GA, Shishkin AA, Gelboin-Burkhart C, Fang MY, Sundararaman B, Blue SM, Nguyen TB, Surka C, Elkins K, et al. 2016. Robust transcriptome-wide discovery of RNA-binding protein binding sites with enhanced CLIP (eCLIP). Nat Methods 13: 508-514. doi:10.1038/nmeth.3810

Wan Y, Zhu N, Lu Y, Wong PK. 2019. DNA transformer for visualizing endogenous RNA dynamics in live cells. Anal Chem 91: 2626-2633. doi:10.1021/acs.analchem.8b02826
Wang C, Han B, Zhou R, Zhuang X. 2016. Real-time imaging of translation on single mRNA transcripts in live cells. Cell 165: 990-1001. doi:10.1016/j.cell.2016.04.040

Wang C, Lu T, Emanuel G, Babcock HP, Zhuang X. 2019a. Imaging-based pooled CRISPR screening reveals regulators of lncRNA localization. Proc Natl Acad Sci 116: 10842 10851. doi:10.1073/pnas.1903808116

Wang P, Tang W, Li Z, Zou Z, Zhou Y, Li R, Xiong T, Wang J, Zou P. 2019b. Mapping spatial transcriptome with light-activated proximity-dependent RNA labeling. Nat Chem Biol 15: 1110 1119. doi:10.1038/s41589-019-0368-5

Weeks DL, Melton DA. 1987. A maternal mRNA localized to the vegetal hemisphere in Xenopus eggs codes for a growth factor related to TGF- $\beta$. Cell 51: 861-867. doi:10.1016/0092-8674 (87)90109-7

Wilk R, Hu J, Blotsky D, Krause HM. 2016. Diverse and pervasive subcellular distributions for both coding and long noncoding RNAs. Genes Dev 30: 594-609. doi:10.1101/gad .276931 .115

Williams CC, Jan CH, Weissman JS. 2014. Targeting and plasticity of mitochondrial proteins revealed by proximity-specific ribosome profiling. Science 346: 748-751. doi:10.1126/sci ence. 1257522

Workman RE, Tang AD, Tang PS, Jain M, Tyson JR, Razaghi R, Zuzarte PC, Gilpatrick T, Payne A, Quick J, et al. 2019. Nanopore native RNA sequencing of a human poly(A) transcriptome. Nat Methods 16: 1297-1305. doi:10.1038/s41592-019$0617-2$

Wu B, Eliscovich C, Yoon YJ, Singer RH. 2016. Translation dynamics of single mRNAs in live cells and neurons. Science 352: 1430-1435. doi:10.1126/science.aaf1084

Wu J, Zaccara S, Khuperkar D, Kim H, Tanenbaum ME, Jaffrey SR. 2019. Live imaging of mRNA using RNA-stabilized fluorogenic proteins. Nat Methods 16: 862-865. doi:10.1038/ s41592-019-0531-7

Wu KE, Parker KR, Fazal FM, Chang H, Zou J. 2020. RNA-GPS predicts high-resolution RNA subcellular localization and highlights the role of splicing. $R N A$ doi:10.1261/rna.074161 .119

Wutz A, Rasmussen TP, Jaenisch R. 2002. Chromosomal silencing and localization are mediated by different domains of Xist RNA. Nat Genet 30: 167-174. doi:10.1038/ng820

Xia C, Fan J, Emanuel G, Hao J, Zhuang X. 2019. Spatial transcriptome profiling by MERFISH reveals subcellular RNA compartmentalization and cell cycle-dependent gene expression. Proc Natl Acad Sci 116: 19490-19499. doi:10.1073/pnas .1912459116

Yan Z, Lecuyer E, Blanchette M. 2019. Prediction of mRNA subcellular localization using deep recurrent neural networks. Bioinformatics 35: i333-i342. doi:10.1093/bioinformatics/ btz337

Zappulo A, van den Bruck D, Ciolli Mattioli C, Franke V, Imami K, McShane E, Moreno-Estelles M, Calviello L, Filipchyk A, Peguero-Sanchez E, et al. 2017. RNA localization is a key determinant of neurite-enriched proteome. Nat Commun 8: 583. doi:10.1038/s41467-017-00690-6

Zhou Y, Wang G, Wang P, Li Z, Yue T, Wang J, Zou P. 2019. Expanding APEX2 substrates for proximity-dependent labeling of nucleic acids and proteins in living cells. Angew Chem Int Ed Engl 58: 11763-11767. doi:10.1002/anie.201905949

Zhu D, Stumpf CR, Krahn JM, Wickens M, Hall TM. 2009. A 5' cytosine binding pocket in Puf3p specifies regulation of mitochondrial mRNAs. Proc Natl Acad Sci 106: 20192-20197. doi:10.1073/pnas.0812079106

Zimyanin VL, Belaya K, Pecreaux J, Gilchrist MJ, Clark A, Davis I, St Johnston D. 2008. In vivo imaging of oskar mRNA transport reveals the mechanism of posterior localization. Cell 134: 843-853. doi:10.1016/j.cell.2008.06.053

Zuckerman B, Ulitsky I. 2019. Predictive models of subcellular localization of long RNAs. RNA 25: 557-572. doi:10.1261/ rna.068288.118 